Thorax (1974), 29, 215.

\title{
Intrathoracic vagus nerve tumours
}

\author{
B ASIL STRICKLAND and M. K. WOLVERSON
}

Department of Diagnostic Radiology, Brompton Hospital, London SW3

\begin{abstract}
Strickland, B. and Wolverson, M. K. (1974). Thorax, 29, 215-222. Intrathoracic vagus nerve tumours. Three new cases of intrathoracic vagus nerve sheath tumour are presented. Two were neurofibromas associated with generalized neurofibromatosis, the third a neurilemmoma. All three presented as tumours of the superior middle mediastinum on the left in close association with the aortic arch. Previously reported cases are reviewed with special reference to the anatomical position and mode of clinical presentation. The tumours most often occur on the proximal part of the nerve close to the aortic arch and more often on the left than the right. They usually present as an incidental finding on a chest radiograph. To explain this anatomical localization it is suggested that the tumours tend to occur on the bulkiest part of the nerve which is in the upper thorax and where there is room for growth which is below the thoracic inlet. Proximal vagal tumours are more easily seen on a chest radiograph than those occurring distally and are therefore more likely to be detected. Symptoms occur only with proximal lesions.
\end{abstract}

Primary tumours of the intrathoracic vagus nerve are rare. Three cases are described which were similar in anatomical position and radiological appearance. Previously reported cases are reviewed with special reference to these features.

\section{CASE REPORTS}

CASE 1 A 32-year-old man presented with hoarseness and dyspepsia for three months and headache for 10 months. A 'mass miniature' chest radiograph taken one year previously was said to be normal. On examination he was found to have generalized cutaneous neurofibromatosis. Chest radiography revealed a mass bulging into the lung from the left upper mediastinum (Fig. 1). It had a clearly defined smooth lateral margin. The trachea was a little displaced to the right. No calcification was visible within the lesion. Lateral views showed it to be situated in the mid mediastinum. An aortogram revealed a normal aorta and main branches separate from the mass. Bronchoscopy showed the left vocal cord to be paralysed but no other abnormality. At thoracotomy a tumour was found in the centre of the superior mediastinum between the left subclavian and left common carotid arteries extending downwards below the arch of the aorta. It was oval in shape and its upper extremity merged with the vagus nerve. Inferiorly, the recurrent laryngeal nerve was stretched around the tumour and the vagus emerged from the lower pole of the mass. That part of the vagus nerve involved by the tumour was resected, the recurrent laryngeal nerve being sacrificed. Histology showed that the tumour was a neurofibroma.

CASE 2 A girl of 21 years was referred because of an abnormality noted in her chest radiograph by the 'mass miniature' radiography service (Fig. 2). She had no symptoms. On examination café-au-lait patches and several neurofibromata were found on the skin. The chest radiograph showed a convex opacity arising from the left side of the mediastinum at the level of the aortic arch and left hilum. It had a clearly defined smooth lateral margin which merged with the aortic arch but seemed separate from the left hilum. A lateral view and tomography indicated a central mediastinal mass bulging downwards and backwards behind the left hilum beneath the aortic arch. A barium swallow and aortogram were normal. At thoracotomy several tumours were found arising from the left vagus nerve. There were four main tumour masses in that part of the nerve between the thoracic inlet and left lung hilum. A further small tumour was present at the lower end of the intrathoracic vagus immediately above the diaphragm. Two small tumour nodules were also present on the phrenic nerve as it coursed over the heart. The portions of the vagus and phrenic nerves involved by the tumours were resected. Histology showed the tumours to be neurofibromata.

CASE 3 A shadow was noted in the routine chest radiograph of a 61-year-old man. He had no symptoms or abnormal physical signs. The chest radiograph 


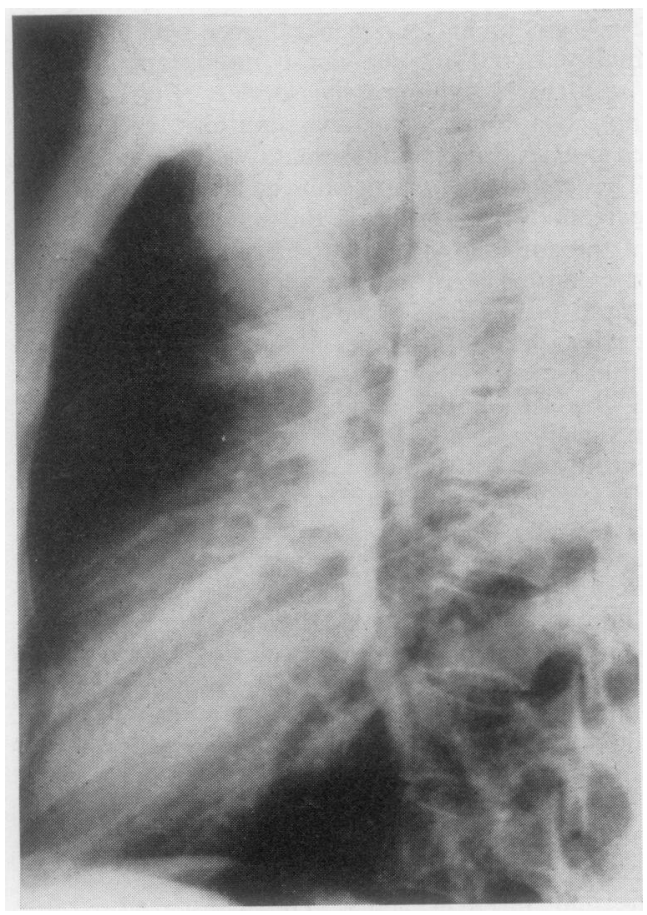

FIG. 1. Case 1. PA and lateral films show the smooth rounded opacity below the inner end of the left clavicle and lying in the central part of the mediastinum. 

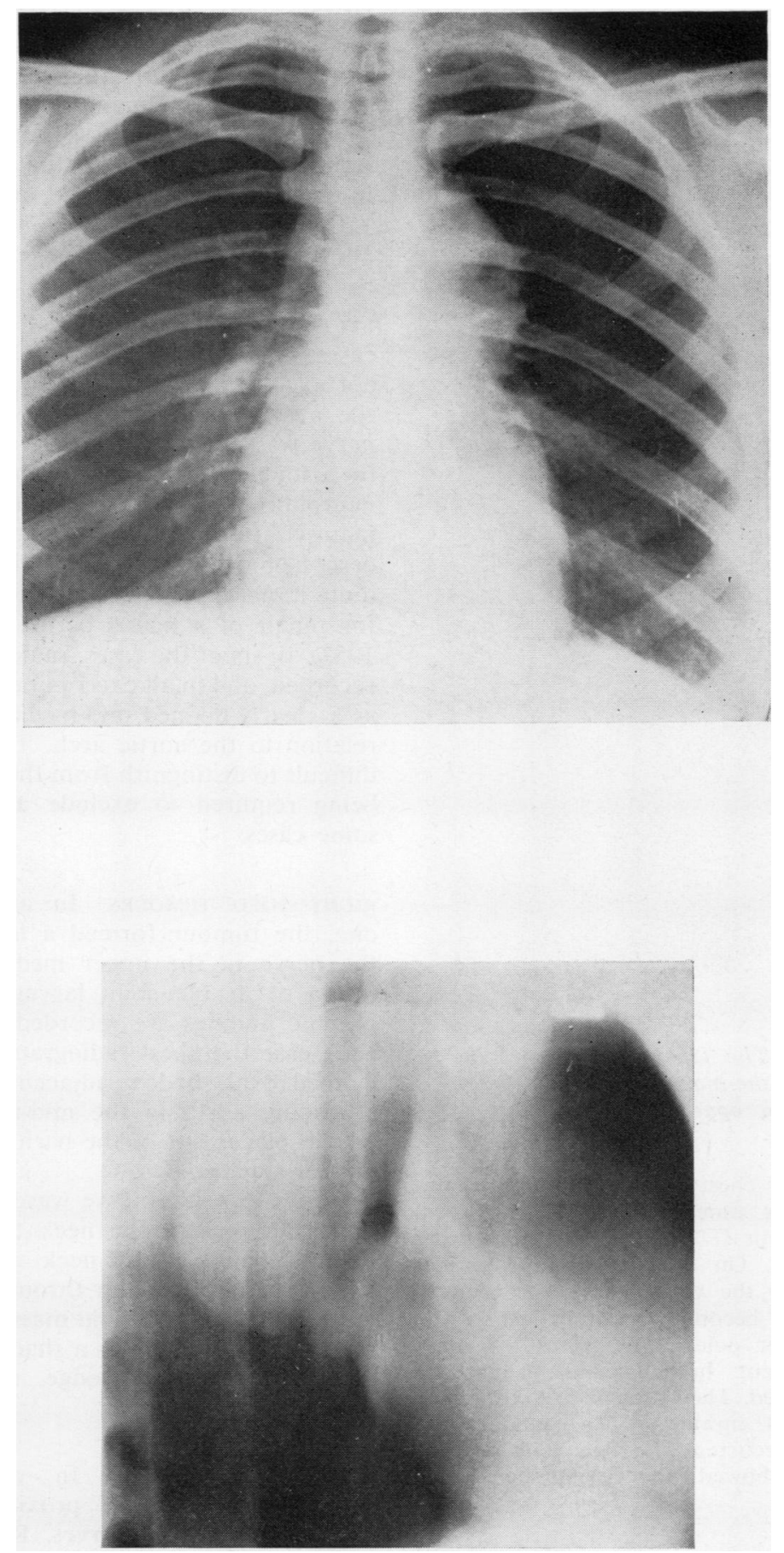

FIG. 2. Case 2. PA film and lateral tomograph showing the smooth convex outline of the opacity. On the lateral projection it cannot be separated from the aortic arch. 
showed a mass bulging into the upper left mediastinum at the level of the aortic arch. The lesion had a clearly defined smooth lateral margin. The aortic arch was clearly seen projected through the shadow and seemed to be separate from it. The trachea was central. A lateral radiograph (Fig. 3) indicated the lesion to be in the central mediastinum overlying and above the aortic arch, its centre being slightly anterior to the trachea.

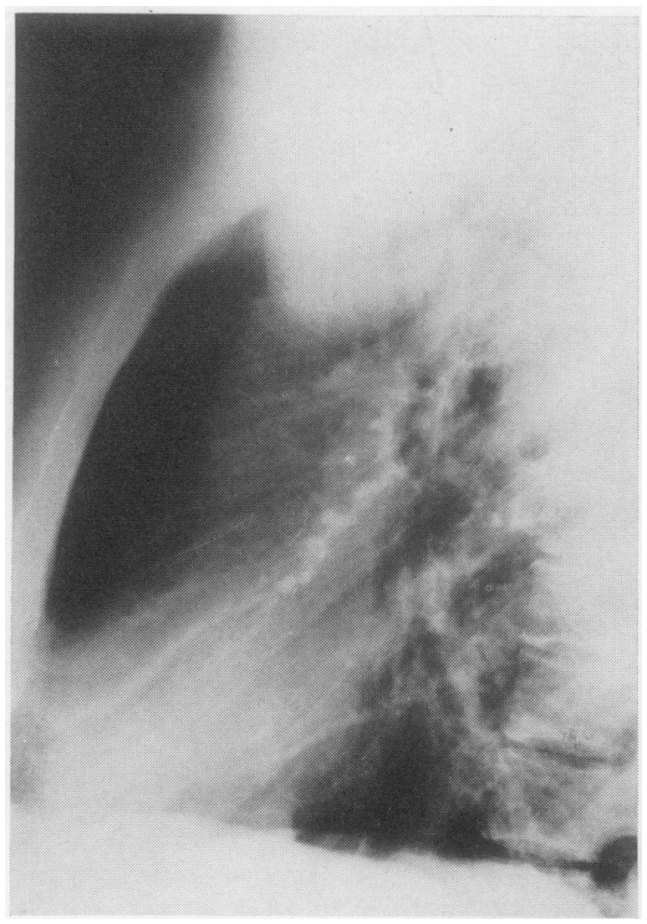

FIG. 3. Case 3. The lateral film shows the central position of the mass in the mediastinum almost identical in appearance with that of case 1 .

Five years later, the chest radiograph appeared unchanged, and at this time thoracotomy was performed. A solid tumour $(7 \times 3 \mathrm{~cm})$ was found lying over the aortic arch. On opening the mediastinal pleura over the mass the vagus nerve was seen to enter its upper pole, becoming entirely lost in the tumour. At the lower pole of the mass the main vagus trunk, recurrent branch, and mediastinal branches were identified. They became lost within the tumour when traced upwards. The tumour was removed and the recurrent laryngeal nerve was divided. Histology showed the lesion to be a neurilemmoma.

\section{DESCRIPTION OF CASES IN THE LITERATURE}

We have found reference to 21 cases of nerve sheath tumours of the intrathoracic vagus nerve.
Of these, the anatomical site of the tumour along the course of the intrathoracic vagus nerve is recorded in 15 . In the remainder the precise $\overline{\bar{\sigma}}$ location of the tumour(s) on the nerve is not $\frac{\Phi}{\vec{D}}$ stated. Of the 15 cases where the anatomical location is recorded the tumour was on the left in nine, on the right in five, and bilateral in one.

Details of these 15 cases and the three recorded above are given in the Table.

LEFT-SIDED TUMOURS In all but one of the nine cases, the tumour was in close relation to the aortic arch and formed a localized expansion of $i v$ the nerve. In some cases, a large length of the $\frac{N}{\mathrm{~N}}$ nerve was affected either by multiple tumours or by a long tapering mass. Multiple tumours were neurofibromata and associated with neurofibro- matosis. In one case the tumour encircled the oesophagus just above the diaphragm. Although $\frac{\hat{\rho}}{\supset}$ quite large, it was not detected before the surgery $\vec{c}$ for repair of a hiatus hernia (Davis and Brown, 1957). In six of the cases, radiographic findings are recorded, and in all except one the lesion appeared as a clearly defined mid-mediastinal mass in close relation to the aortic arch. The lesion was often $\overline{\bar{O}}$ difficult to distinguish from the aorta, aortography 응 being required to exclude a vascular lesion in some cases.

RIGHT-SIDED TUMOURS In all six cases except one, the tumour formed a localized swelling of the nerve in the upper mediastinum below the $\overrightarrow{\overrightarrow{0}}$ origin of its recurrent laryngeal branch. Radiographic findings are recorded in all six cases. In $\underset{\sigma}{-}$ each case the chest radiograph revealed a clearly 3 defined oval shadow adjacent to and above the ascending aorta in the mid-mediastinum. There $\frac{0}{3}$ was displacement of the barium-filled oesophagus and/or trachea.

In one case the nerve was extensively involved from the root of the neck to the hilum of the lung. A mass in the neck was connected by aN narrow band of tumour through the thoracic inlet to a superior mediastinal mass which appeared on N the chest radiograph as a shadow bulging into the lung field (Penido, Dodge, Clagget, and Starr, 1957).

BILATERAL TUMOURS In one case multiple tumours involved the proximal parts of botho무 intrathoracic vagus nerves. Radiography showed nodular soft tissue shadows projecting laterally from the mid-mediastinum on both sides at the $\frac{}{\sigma}$ level of the aortic arch. This is the only case in 
T A B L E

\begin{tabular}{|c|c|c|c|c|c|}
\hline & DIRCRAM & Ppisticical & $\frac{x-\operatorname{Rax}}{x+\operatorname{los}}$ & 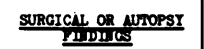 & PAT:DOOTY \\
\hline $\begin{array}{l}\text { LOT SIDP TUEOURS } \\
\text { CASE } 1 \\
\text { Ror. } 1\end{array}$ & & $\begin{array}{l}\hat{\delta} \quad 35 \text { yrs. } \\
\text { Rout ine CxR. } \\
\text { Cafe au lait patches } \\
\text { exillas and chest. }\end{array}$ & $\begin{array}{l}\text { Widen ing of the } \\
\text { apperior mod iast inum } \\
\text { to loft. }\end{array}$ & $\begin{array}{l}\text { Theour of syopethetic } \\
\text { chein. } \\
\text { Theours on vague. } \\
\text { 1) On eorta. } \\
\text { 2) Imediately below } \\
\text { eorta. }\end{array}$ & $\begin{array}{l}\text { Yourofibrome of } \\
\text { eyperthot tic chain } \\
\text { and vague norvo. }\end{array}$ \\
\hline $\begin{array}{l}\text { CASE } 2 \\
\text { Rof. } 5\end{array}$ & & $\begin{array}{l}\delta \\
\text { yo statement of } \\
\text { cl inical presentation. }\end{array}$ & Ho statement. & $\begin{array}{l}\text { Tuwour involving } \\
\text { I.R.L.A. Io further } \\
\text { dotalle. }\end{array}$ & Meurinome. \\
\hline $\begin{array}{l}\text { CASE } 3 \\
\text { Rer. } 7\end{array}$ & & $\begin{array}{l}24 \text { yrs. } \\
\text { Rout ine CxR. } \\
\text { Multiple Cafe au lait } \\
\text { patches and cut laneous } \\
\text { neurofibromas. }\end{array}$ & "Xed iast inal Kasz" & $\begin{array}{l}\text { Lares mass above and } \\
\text { overlying aorta. } \\
\text { Three saall tumour } \\
\text { nodules on nerve } \\
\text { just below main mess. }\end{array}$ & Neurofibromes. \\
\hline $\begin{array}{l}\text { CASE } 4 \\
\text { Rof. } 14\end{array}$ & & $\begin{array}{l}\hat{\delta} \\
\text { Rout ine } \\
\text { CxR. }\end{array}$ & $\begin{array}{l}\text { Oval soft } t \text { issue } \\
\text { shadow left mid } \\
\text { med iast inum, just } \\
\text { above main pulmonary } \\
\text { artery. }\end{array}$ & $\begin{array}{l}\text { Tumour at level of } \\
\text { aortic arch. }\end{array}$ & Meurofibrome. \\
\hline $\begin{array}{l}\text { Coss } 5 \\
\text { Rer. } 3\end{array}$ & & $\begin{array}{l}\text { P } 55 \text { yrs. } \\
\text { Chronic Pe. } \\
\text { deficiency anaemia } \\
\text { associated with } \\
\text { hiatus hernia. }\end{array}$ & $\begin{array}{l}\text { Fixed hiatus hernia } \\
\text { with fluid level on } \\
\text { CaR. } \\
\text { Mo sien of turour. }\end{array}$ & $\begin{array}{l}\text { Tumour just above } \\
\text { diaphrag encircl ing } \\
\text { oesophagus and } \\
\text { adherent to hiatus } \\
\text { hemia. }\end{array}$ & Neurof ibroma. \\
\hline $\begin{array}{l}\text { Cass } 6 \\
\text { Rer. } 13\end{array}$ & & $\begin{array}{l}\delta \quad 64 \text { yrs. } \\
\text { Neurofibromatosis. } \\
\text { No statement. } \\
\text { Clinical presentation. }\end{array}$ & Ho Statement. & $\begin{array}{l}\text { Mult tiple tumours on } \\
\text { nerve at level of } \\
\text { aortic arch. }\end{array}$ & Meurof ibromes. \\
\hline $\begin{array}{l}\text { CASE } 7 \\
\text { Rer. } 2 .\end{array}$ & & $\begin{array}{l}f \quad 45 \text { yrs. } \\
\text { Hoarseneas due to } \\
\text { vocal coard paralysis } \\
4 \text { yrs. }\end{array}$ & Ho statement. & No statement. & "Schmannoma" \\
\hline $\begin{array}{l}\text { Cass } 8 \\
\text { Rot. } 4\end{array}$ & & $\begin{array}{l}\text { J } 35 \text { yrs. } \\
\text { Rout ine } \text { cxR. }\end{array}$ & $\begin{array}{l}\text { nlargoment of } \\
\text { aortic knuckle } \\
\text { proved non-vascular } \\
\text { by angio-cardiography. }\end{array}$ & $\begin{array}{l}\text { Pusifore mase } \\
\text { extend ing from } \\
\text { thorasic inlet to } \\
\text { left hilum. }\end{array}$ & Mourilemoma. \\
\hline $\begin{array}{l}\text { Cust } 9 \\
\text { Ref. } 4\end{array}$ & & 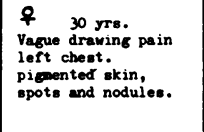 & $\begin{array}{l}\text { Paracardiac shadou } \\
\text { adjacomt to hortic } \\
\text { knuckle and round } \\
\text { mass ot level of } \\
\text { 4th rib anteriorly. }\end{array}$ & $\begin{array}{l}\text { Tumour just below } \\
\text { aortic arch. } \\
\text { Second turour on } \\
\text { anterior end of } \\
\text { left 4th inter- } \\
\text { costal nerve. }\end{array}$ & $\begin{array}{l}\text { Meurof } i \text { bromas of } \\
\text { vague and inter- } \\
\text { coetal norves. }\end{array}$ \\
\hline & & & & & \\
\hline
\end{tabular}

contd. 
T A B L E-contd.

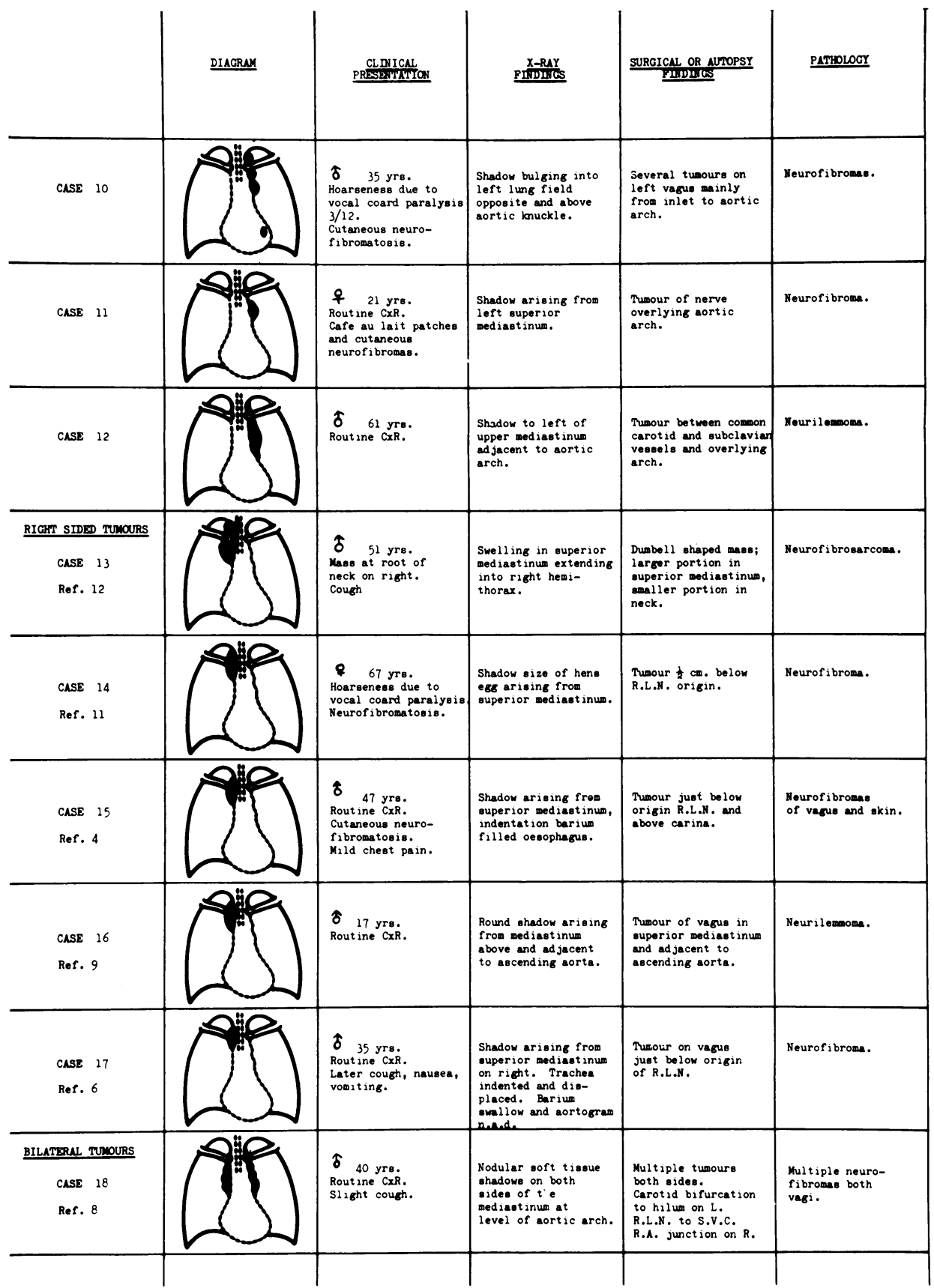

Diagrammatic representation of the anatomical site in each case is recorded in column 2. The numbered references correspond to those listed on p. 222. 
which multiple nerve tumours were unassociated with other stigmata of neurofibromatosis.

Clinical PRESEntation Of the 18 cases, 10 were discovered incidentally at routine chest radiography. Three patients presented with hoarseness due to recurrent laryngeal nerve dysfunction. One patient presented with vague chest pain and cough and one with a mass at the root of the neck. In the remainder the lesion was an incidental finding at necropsy or surgery.

\section{DISCUSSION}

Neural tumours of the mediastinum are quite common and account for between 19 and $39 \%$ of all intrinsic mediastinal lesions (Ecker, Timmes, and Miscall, 1963). Such tumours may arise from nerve cells or nerve sheaths. The usual site of origin is an intercostal nerve or the sympathetic chain. However, tumours of the intrathoracic vagus nerve are very uncommon and when they occur at this site the tumours are of the nerve sheath type.

Nerve sheath tumours are of two types, neurilemmomas and neurofibromas. Neurilemmomas are encapsulated lesions and histologically have a well organized architecture of cellular and reticular tissue. They may undergo cyst formation and necrosis. Neurofibromas are nonencapsulated with a poorly organized structure histologically and contain neurites (Gayola, Janis, and Weil, 1965).

In previously recorded cases a definite statement of the histological type of nerve sheath tumour was not always given because some pathologists disagree on classification. Of the 25 intrathoracic vagal nerve sheath tumours reported, however, including our own three cases, 14 were confidently stated to be neurofibromas and of these eight were associated with neurofibromatosis. Seven cases were stated to be neurilemmomas. No case of neurilemmoma of the vagus has been associated with von Recklinghausen's disease of nerves.

A case of malignant nerve sheath tumour of the intrathoracic vagus was reported by Penido et al., in 1957, although the authenticity of this case has been questioned by Gayola et al. (1965).

ANATOMICAL FEATURES The constancy with which the tumours have occurred in close proximity to the aortic arch requires explanation. We believe this is related partly to the anatomical course of the intrathoracic vagus nerve and partly to the way in which these tumours present clinically.
ANATOMICAL FEATURES OF VAGUS NERVE IN CHEST The vagus nerve in the chest passes from the thoracic inlet to the oesophageal hiatus in the diaphragm. A single main trunk exists only as far as the posterior aspect of the hilum of the lung. Here the nerve breaks up to form the posterior pulmonary plexus from which branches arise to innervate the lung before the oesophageal plexus is formed. A single vagus trunk is again formed before the nerve enters the abdomen. Vagal tumours tend to occur on the proximal, thickest part of the nerve where all the neurones and connective tissue are present as a single trunk and before the origin of its major intrathoracic branches. This proximal trunk forms a lateral relation of the aortic arch on the left and a posterior relation on the right.

The recurrent laryngeal nerve on the left arises at the level of the aortic arch and on the right in the root of the neck. The proximal intrathoracic vagal trunk is thus thicker on the left than on the right. This may explain why the vagal nerve tumours have occurred in the chest twice as often on the left as on the right.

A tumour arising near the thoracic inlet has little room for expansion and tends to grow into the root of the neck or downwards into the mediastinum towards the aortic arch. In the case described by Parella (1950), the tumour had a dumbbell shape, growth having occurred in both directions leaving a narrow band of tumour at the level of the thoracic inlet.

MODE OF Clinical PRESENTATION IN RELATION TO SITE These tumours have usually been detected as incidental findings at chest radiography. Eight of the previously reported cases and two of our cases presented in this way. To produce a recognizable shadow in a chest radiograph a tumour of the vagus must displace the mediastinal pleura. The proximal trunk of the nerve is in close proximity to the mediastinal pleura which will be displaced by a small lesion. A tumour arising from the lower part of the nerve might be obscured by the hilum or heart and be less readily seen unless a high kilovoltage technique is used. For example, the tumour reported by Davis and Brown (1957) encircled the lower oesophagus and was not seen in a preoperative chest radiograph.

Those tumours presenting with symptoms all occurred on the proximal part of the nerve. Hoarseness due to vocal cord paralysis will occur only if the tumour arises proximal to the origin of the recurrent laryngeal nerve. Chest pain and 
cough are most likely to occur with lesions in the vicinity of the trachea and major bronchi than at a lower position in the mediastinum.

We wish to record our sincere thanks to the consultant surgeons on the staff of Brompton Hospital.

\section{REFERENCES}

Blades, B. and Dugan, D. J. (1943). Resection of the left vagus nerve for multiple intrathoracic neurofibromas. Journal of the American Medical Association, 123, 409. (Ref. 1)

Carey, L. S., Ellis, F. H. Jr., Good, C. A., and Woolner, L. B. (1960). Neurogenic tumors of the mediastinum: a clinicopathologic study. American Journal of Roentgenology, 84, 182. (Ref. 2)

Davis, C. Jr. and Brown, C. (1957). Intrathoracic neurofibroma of the vagus nerve associated with a diaphragmatic hernia. Journal of Thoracic and Cardiovascular Surgery, 33, 532. (Ref. 3)

Ecker, R. R., Timmes, J. J., and Miscall, L. (1963). Neurogenic tumors of the intrathoracic vagus nerve. Archives of Surgery, 86, 222. (Ref. 4)

Efskind, L. and Liavaag, K. (1950). Intrathoracic neurogenic tumors. Journal of Thoracic Surgery, 20, 13. (Ref. 5)

Gayola, G., Janis, M., and Weil, P. H. (1965). Intrathoracic nerve sheath tumor of the vagus. Journal of Thoracic and Cardiovascular Surgery, 49, 412. (Ref. 6)
Gerbode, F. and Marguiles, G. S. (1953). Neurofibromatosis with intrathoracic neurofibromas of the vagus nerve. Journal of Thoracic and Cardiovascular Surgery, 25, 429. (Ref. 7)

Gilbertsen, V. A. and Lillehei, C. W. (1954). Bilateral intrathoracic neurofibromas of the vagus nerves with a note on the physiologic effects of cervico- is thoracic vagectomy in man: a case report. Journal of Thoracic Surgery, 28, 78. (Ref. 8)

Moehlig, R. C. and Jarkowski, T. L. (1964). Neurilemmoma of the vagus nerve in the posterior mediastinum. Journal of Michigan State Medical Society, 63, 442. (Ref. 9)

Oberman, H. A. and Abell, M. R. (1960). Neuro- đ̃ genous neoplasms of the mediastinum. Cancer, i 13, 882. (Ref. 10)

Pampari, D. and Lacerenza, C. (1959). A case of $\vec{G}$ neurofibroma of the intrathoracic vagus nerve in $\mathrm{O}$ a woman with von Recklinghausen's disease. Surgery, 45, 470. (Ref. 11)

Parella, G. S. (1950). Neurofibrosarcoma of the vagus nerve. New England Journal of Medicine, 242, 324. (Ref. 12)

Penido, J., Dodge, H. W., Clagett, O. T., and Starr, G. F. (1957). Proceedings of the Mayo Clinic, 32, 239. (Ref. 13)

Tuttle, W. M., Sanai, V., and Harms, H. P. (1956). Intrathoracic neurofibroma of the vagus nerve. Journal of Thoracic Surgery, 31, 632. (Ref. 14)

Requests for reprints to: Dr. B. Strickland, Department of Diagnostic Radiology, Brompton Hospital, London SW3. 